\title{
The efficacy and safety of high-flow nasal cannula therapy in patients with COPD and type II respiratory failure: a meta-analysis and systematic review
}

\author{
Zhiping $\mathrm{Xu}^{\dagger}$, Lingxia Zhu ${ }^{\dagger}$, Jingye Zhan and Lijun Liu*
}

\begin{abstract}
Background: High-flow nasal cannula (HFNC) and noninvasive ventilation (NIV) have been used for the treatment of COPD and respiratory failure in clinical settings. We aimed to evaluate the efficacy and safety of HFNC therapy in patients with COPD and type II respiratory failure, to provide evidence to the clinical COPD management.

Methods: We searched Cochrane et al. databases up to Dec 31, 2020 for randomized controlled trials (RCTs) on the use of HFNC therapy in patients with COPD and type II respiratory failure. Two researchers independently screened the literature according to the inclusion and exclusion criteria, and evaluated the quality of the literature and extracted data. We used Revman5.3 software for statistical analysis of collected data.

Results: A total of 6 RCTs involving 525 COPD and type II respiratory failure patients. Meta-analyses indicated that compared with NIV, HFNC could significantly reduce $\mathrm{PaCO}_{2}$ level $(\mathrm{MD}=-2.64,95 \% \mathrm{Cl}(-3.12$ to -2.15$))$, length of hospital stay ((MD $=-1.19,95 \mathrm{Cl}(-2.23$ to -0.05$))$, the incidence of nasal facial skin breakdown $((\mathrm{OR}=0.11$, $95 \% \mathrm{Cl}(0.03-0.41))$. And there were no significant differences between the two groups in $\mathrm{PaO}_{2}((\mathrm{MD}=2.92,95 \% \mathrm{Cl}$ $(-0.05$ to 5.90$))$, incidence of tracheal intubation $((\mathrm{OR}=0.74,95 \% \mathrm{Cl}(0.34-1.59))$ and mortality $(\mathrm{OR}=0.77,95 \% \mathrm{Cl}$ $(0.28-2.11))$.

Conclusions: HFNC is more advantageous over NIV in the treatment of COPD and type II respiratory failure. Future studies with larger sample size and strict design are needed to further elucidate the role of HFNC in COPD and respiratory failure.
\end{abstract}

Keywords: HFNC, COPD, Respiratory failure, Ventilation, Treatment, Review

\section{Background}

Chronic obstructive pulmonary disease (COPD) is a common chronic disease characterized by persistent airflow limitation [1]. There are nearly 100 million COPD patients in China, and the prevalence of COPD in people

\footnotetext{
${ }^{*}$ Correspondence: liulijun@tom.com

'Zhiping Xu and Lingxia Zhu are equal contributors

Department of Emergency and Critical Care Medicine, The Second Affiliated Hospital of Soochow University, No.1055, San Xiang Road, Suzhou, Jiangsu Province, China
}

over 40 years old is $13.7 \%$ [2, 3]. Acute exacerbation of COPD and complications are the main causes of death [4]. Oxygen therapy is the main treatment method for patients with COPD and hypoxemia [5]. Traditional oxygen therapy uses low-flow oxygen, but some patients' hypoxia or hypercapnia are difficult to correct, and noninvasive ventilation (NIV) has gradually become the gold standard for the treatment of patients with AECOPD and type II respiratory failure [6]. However, the design of NIV masks and nasal masks has disadvantages such as original author(s) and the source, provide a link to the Creative Commons licence, and indicate if changes were made. The images or other third party material in this article are included in the article's Creative Commons licence, unless indicated otherwise in a credit line to the material. If material is not included in the article's Creative Commons licence and your intended use is not permitted by statutory regulation or exceeds the permitted use, you will need to obtain permission directly from the copyright holder. To view a copy of this licence, visit http://creativecommons.org/licenses/by/4.0/. The Creative Commons Public Domain Dedication waiver (http://creativeco mmons.org/publicdomain/zero/1.0/) applies to the data made available in this article, unless otherwise stated in a credit line to the data. 
facial compression, affecting patient communication, eating and sleep [7, 8]. The poor comfort and mask intolerance can easily lead to tracheal intubation and cause NIV treatment failure [9].

High-flow nasal cannula (HFNC) is a new type of noninvasive respiratory assistance method. It can reduce $\mathrm{PaCO}_{2}$ by using the flushing effect of high flow and adjust the oxygen flow and oxygen concentration separately to avoid the high concentration of oxygen causing respiratory depression in patients $[10,11]$. HFNC can improve ventilation and oxygenation and improve comfort by providing oxygen that is heated and humidified with precise oxygen concentration [12]. Studies [13-15] have shown that the use of HFNC oxygen therapy for COPD patients can reduce the frequency of exacerbations and improve exercise capacity and quality of life. Some studies [14, 16] have also shown that HFNC can improve oxygenation in patients with COPD. However, several studies have shown that HFNC can be used in patients with AECOPD and type II respiratory failure, but it has no effect on the incidence of patients' tracheal intubation, length of hospital stay, and incidence of adverse events. The effects and safety of HFNC treatment in patients with COPD and type II respiratory failure remain unclear. Therefore, we aimed to conduct a meta-analysis of the application of HFNC in the treatment of patients with COPD and type II respiratory failure, to evaluate the efficacy and safety of HFNC, thereby providing a basis for the clinical treatment of COPD and respiratory failure.

\section{Methods}

We conducted and reported this meta-analysis and systematic review in compliance with the preferred reporting items for systematic reviews and meta-analyses (PRISMA) [17].

\section{Search strategy}

We searched the Cochrane Clinical Trials Database, EMBASE, CINAHL, PubMed, web of science, Wanfang, and Weipu Knowledge Network for randomized controlled trials(RCTs). The search time limit is from the establishment of the database to Dec 31, 2020. We used following search terms: ("high flow nasal cannula" OR "HFNC" OR "high flow nasal oxygen" OR "high flow oxygen therapy" OR "high flow nasal cannula oxygen therapy") AND ("Pulmonary Disease" OR "Chronic Obstructive" OR "Chronic Obstructive Pulmonary Disease" OR "Chronic Obstructive Lung Disease" OR "COPD" OR "Chronic Obstructive Airway Disease" OR "COAD" OR "chronic airflow obstructions" OR "pulmonary emphysema"). At the same time, we traced the relevant references of the included literature as a supplement to further search the possibly relevant literature.

\section{Inclusion and exclusion criteria}

The RCT inclusion criteria for this meta-analysis were: (1) the research populations were COPD patients with type II respiratory failure; (2) age $\geq 18$ years; (3) intervention measures: HFNC was used in the experimental group, and NIV was used in the control group; (4) the main outcome indicators such as $\mathrm{PaCO}_{2}, \mathrm{PaO}_{2}$ et al. had been reported; (5) RCT study design; (6) Chinese and English literature.

The exclusion criteria were: (1) randomized crossover studies; (2) before-and-after control study; (3) studies with incomplete data, which could not be extracted and included for synthesized analysis.

\section{Literature screening}

We imported the retrieved literatures into the ENDNOTE software, and we checked the duplicates based on the title, authors and year of the documents. Two researchers independently reviewed each of the retrieved documents. According to the inclusion and exclusion criteria, the documents were initially screened by reading titles and abstracts, and then the preliminary screening documents were further screened by reading the full text. If any differences were encountered, two authors discussed for consents. If the negotiation still could not be unanimous, and a third researcher would resolve by arbitration.

\section{Quality evaluation}

The quality of RCT was evaluated using Cochrane's risk of bias assessment tool [18], including evaluation of random sequence generation, allocation concealment, blinding of patients and interveners, blinding of outcome measurers, incomplete outcome data, selective reports and other potential bias. Each item was rated as "low risk", "high risk" or "unclear". When the evaluation results of the two investigators were inconsistent, the third investigator would make the decision.

\section{Data processing}

We used Revman5.3 software for statistical analysis of data, and used $I^{2}$ statistics and Cochrane $Q$ test to assess whether there was heterogeneity between studies. The Cochrane $Q$ test showed statistically significant heterogeneity when $P<0.1$ and $I^{2} \geq 50 \%$, and the random effects model was used. When the heterogeneity between the studies was not significant $(P>0.1$, $\left.I^{2}<50 \%\right)$, the fixed effects model was used. Binary data were expressed by odds ratio (OR) and 95\% confidence interval (95\% CI), and continuous data were expressed 
by weighted mean difference (MD). When $P<0.05$, the difference between groups was statistically significant.

\section{Results}

\section{Included RCTs}

One hundred and eight related documents were initially retrieved through the databases after removing duplicate reports, after reading the titles and abstracts, 38 reports were sent out for full-text review. 32 studies were excluded since the documents that did not meet the inclusion criteria. Finally, 6 RCTs [19-24] were included. The study selection process is shown in Fig. 1. Of the 6 included RCTs, a total of 525 COPD patients were included, 259 patients underwent the HFNC treatment, and 266 patients underwent NIV treatment. The basic information of the included RCTs is shown in Table 1.

\section{Quality of included RCTs}

Among the 6 included RCTs, 3 studies [19-21] clearly mentioned the method of using computer random sequence, and none of them mentioned allocation concealment. Due to the difference in oxygen therapy devices, it was difficult to blind the study patients and interveners, and all the research items were evaluated as having a high risk of bias. Since most of the outcome indicators are objective indicators, even if the evaluators are not blinded, they would not have a significant impact on the results. The blinding of outcome assessment in one study [19] was evaluated as low risk of bias. There were no other risks of bias in the results of all studies were found. The risk of bias results are shown in Figs. 2 and 3.

\section{Meta-analyses \\ $\mathrm{PaCO}_{2}$}

Five RCTs [20-24] compared the effects of HFNC and NIV on $\mathrm{PaCO}_{2}$ after $24 \mathrm{~h}$ of oxygen therapy. There was no heterogeneity between the studies $\left(I^{2}=0 \%, P=0.59\right)$, and the fixed effects model was used for analysis. The results showed that compared with NIV, HFNC could
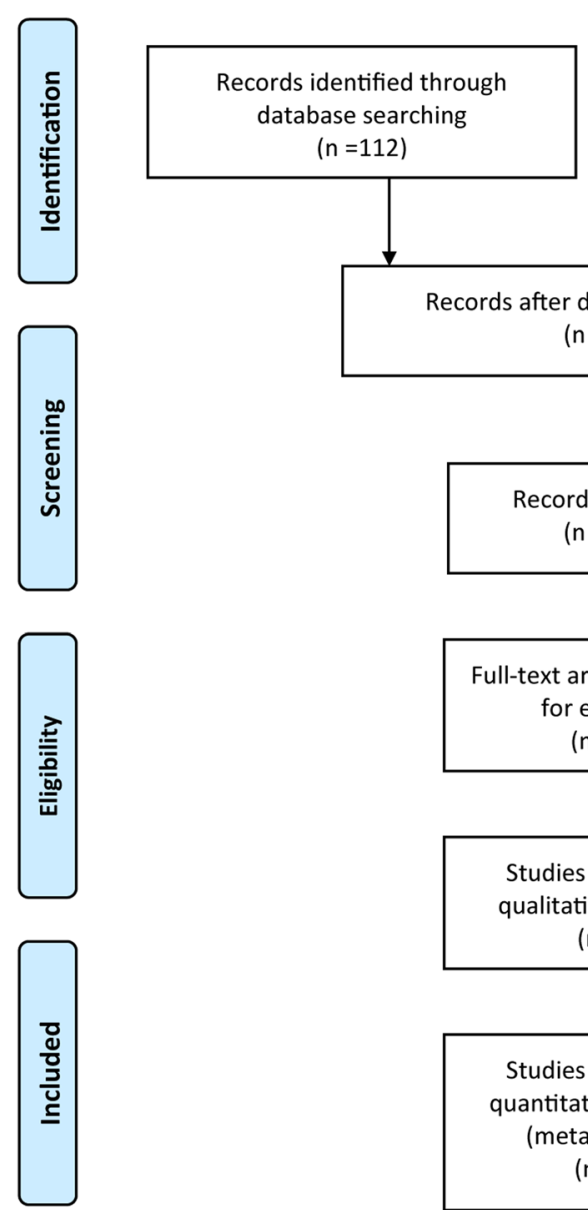

Records after duplicates removed $(n=108)$

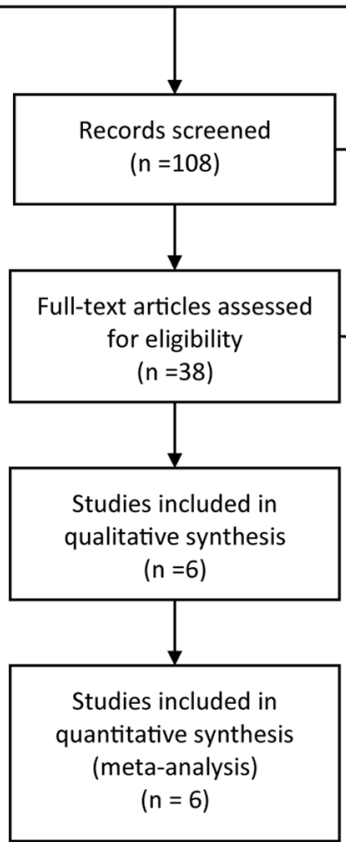

Fig. 1 The PRISMA flow diagram of study selection 
Table 1 The characteristics of included RCTs

\begin{tabular}{|c|c|c|c|c|c|c|}
\hline \multirow[t]{2}{*}{ RCT } & \multirow[t]{2}{*}{ Country } & \multicolumn{2}{|l|}{ Sample size } & \multicolumn{2}{|l|}{ Intervention } & \multirow[t]{2}{*}{ Outcomes } \\
\hline & & $\begin{array}{l}\text { Experimental } \\
\text { group }\end{array}$ & Control group & $\begin{array}{l}\text { Experimental } \\
\text { group }\end{array}$ & Control group & \\
\hline Ping 2018 & China & 47 & 46 & HFNC & NIV & $\begin{array}{l}\text { Incidence of tracheal intubation, mortality, incidence of } \\
\text { nasal facial skin breakdown }\end{array}$ \\
\hline Wang 2019 & China & 32 & 31 & HFNC & NIV & Incidence of tracheal intubation, length of hospital stay \\
\hline Jing 2018 & China & 38 & 37 & HFNC & NIV & $\begin{array}{l}\mathrm{PaCO}_{2}, \mathrm{PaO}_{2} \text {, Incidence of tracheal intubation, length of } \\
\text { hospital stay }\end{array}$ \\
\hline Jiang 2019 & China & 50 & 50 & HFNC & NIV & $\begin{array}{l}\mathrm{PaCO}_{2}, \mathrm{PaO}_{2} \text {, Incidence of tracheal intubation, length of } \\
\text { hospital stay, mortality }\end{array}$ \\
\hline Guo 2018 & China & 34 & 54 & HFNC & NIV & $\begin{array}{l}\mathrm{PaCO}_{2}, \mathrm{PaO}_{2} \text {, Incidence of tracheal intubation, length of } \\
\text { hospital stay }\end{array}$ \\
\hline Chen 2020 & China & 48 & 48 & HFNC & NIV & $\mathrm{PaCO}_{2}, \mathrm{PaO}_{2}, \mathrm{pH}$, Incidence of tracheal intubation mortality \\
\hline
\end{tabular}

Arterial blood oxygen partial pressure $\left(\mathrm{PaO}_{2}\right)$, carbon dioxide partial pressure $\left(\mathrm{PaCO}_{2}\right)$

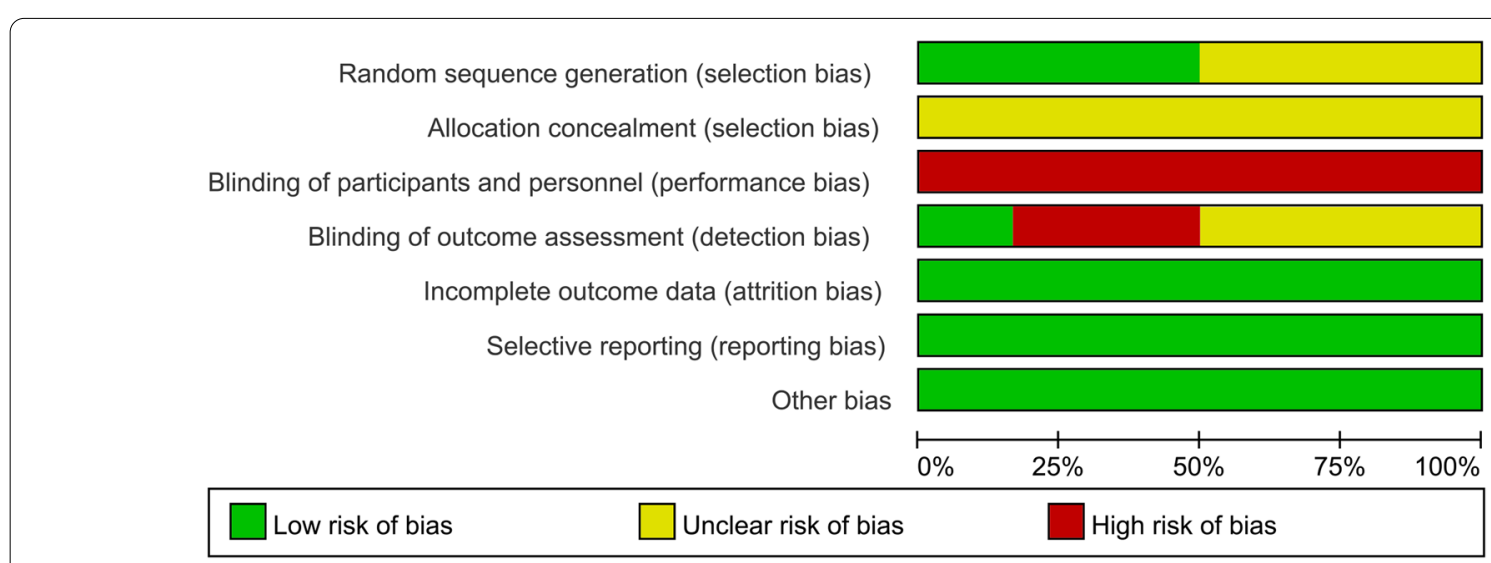

Fig. 2 Risk of bias graph

significantly reduce $\mathrm{PaCO}_{2}$ level $(\mathrm{MD}=-2.64,95 \% \mathrm{CI}$ ( -3.12 to -2.15$), Z=10.60, P<0.001$, Fig. $4 \mathrm{~A})$.

$\mathrm{PaO}_{2}$

Five RCTs [20-24] compared the effects of HFNC and NIV on $\mathrm{PaO}_{2}$ after $24 \mathrm{~h}$ of oxygen therapy. There was heterogeneity between the studies $\left(I^{2}=81 \%, P<0.001\right)$, and the random effects model was used for analysis. The results showed that the difference between the two groups in $\mathrm{PaO}_{2}$ was not statistically significant $(\mathrm{MD}=2.92$, 95\% CI ( -0.05 to 5.90$), Z=1.93, P=0.05$, Fig. 4B).

\section{The incidence of tracheal intubation}

Five RCTs [19, 20, 22-24] compared the effects of HFNC and NIV on the incidence of tracheal intubation. There was no heterogeneity between the studies $\left(I^{2}=0 \%\right.$, $P=0.87)$, and the fixed effects model was used for analysis. The results showed that the difference between the two groups in the incidence of tracheal intubation was not statistically significant $(\mathrm{OR}=0.74,95 \% \mathrm{CI}(0.34-$ 1.59), $Z=0.78, P=0.44$, Fig. $4 C$ ).

\section{The length of hospital stay}

Four RCTs [19, 20, 22, 24] compared the effects of HFNC and NIV on the length of hospital stay. There was heterogeneity between the studies $\left(I^{2}=56 \%, P=0.08\right)$, and the random effects model was used for analysis. The results showed that compared with NIV, HFNC could significantly reduce the length of hospital stay $(\mathrm{MD}=-1.19$, $95 \%$ CI ( -2.23 to -0.05$), Z=2.05, P=0.04$, Fig. $5 \mathrm{~A})$.

\section{The incidence of nasal facial skin breakdown}

Two RCTs [19, 21] compared the effects of HFNC and NIV on the incidence of nasal facial skin breakdown. There was no heterogeneity between the studies $\left(I^{2}=0 \%\right.$, $P=0.79$ ), and the fixed effects model was used for 


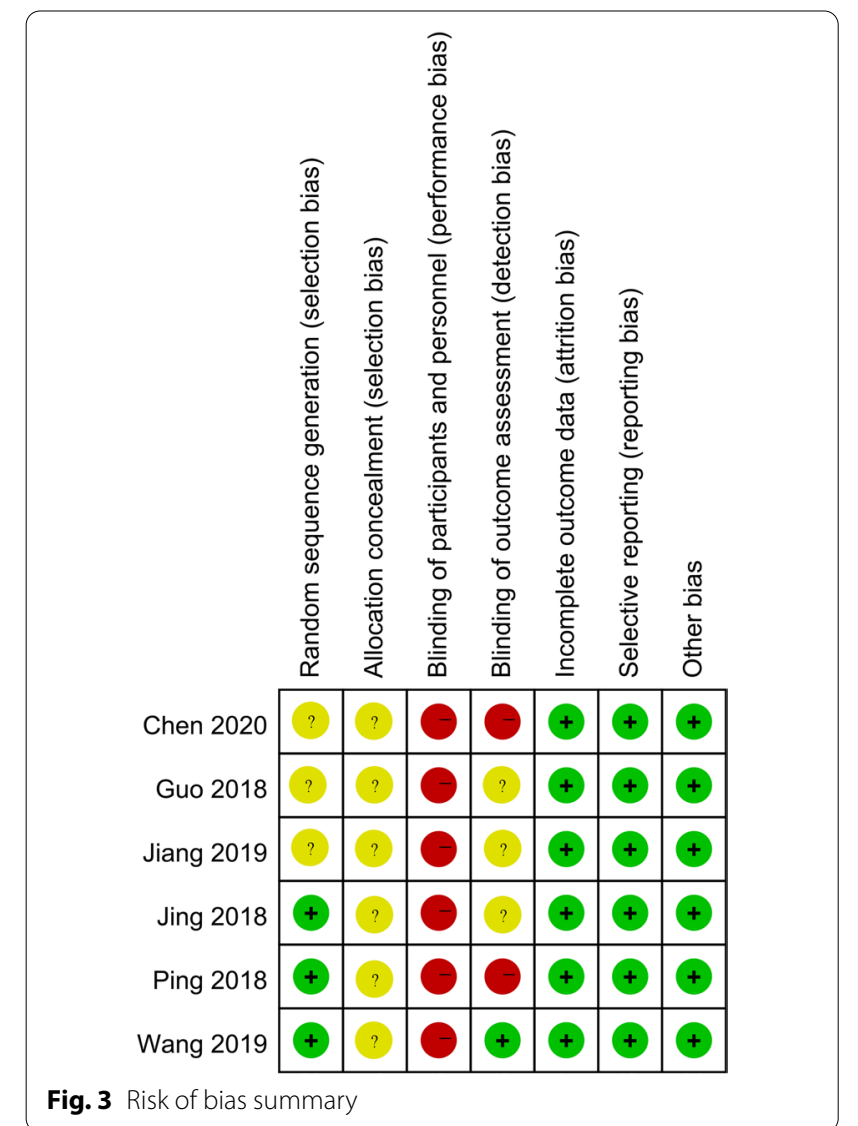

analysis. The results showed that compared with NIV, HFNC could significantly reduce the incidence of nasal facial skin breakdown $(\mathrm{OR}=0.11,95 \%$ CI (0.03-0.41), $Z=0.51, P=0.61$, Fig. 5B).

\section{Mortality}

Two RCTs [23, 24] compared the effects of HFNC and NIV on the mortality. There was no heterogeneity between the studies $\left(I^{2}=0 \%, P=0.69\right)$, and the fixed effects model was used for analysis. The results showed that the difference between the two groups in the mortality was not statistically significant $(\mathrm{OR}=0.77,95 \% \mathrm{CI}$ (0.28-2.11), $Z=0.51, P=0.61$, Fig. 5C).

\section{Discussion}

The main reason for the hospitalization of COPD patients is due to the continuous progress of the disease and severe respiratory failure [18]. Emergency tracheal intubation is often used during the treatment process, and invasive ventilator-assisted ventilation is required [25]. HFNC oxygen therapy is a new type of treatment that can provide patients with stable oxygen concentration, improve mucosal clearance, prevent nasopharyngeal dead space and open alveoli, so it has great clinical promotion value [26]. The main factors of organ dysfunction in patients with type II respiratory failure are respiratory acidosis, hypercapnia and hypoxemia [27]. When the $\mathrm{PaCO}_{2}$ level in the body rises to a certain level, the $\mathrm{PaO}_{2}$ level usually decreases, leading to cardiac arrest, pulmonary heart disease, etc., which will have a serious impact on the life of the patient $[28,29]$. However, $\mathrm{PaCO}_{2}$ is used to determine the ventilation status of the alveoli, and its increase indicates that the lungs are insufficiently ventilated. $\mathrm{PaO}_{2}$ is a sensitive indicator of hypoxia in the body. Decreased $\mathrm{PaO}_{2}$ is seen in ventilation dysfunction. $\mathrm{PaCO}_{2}$ and $\mathrm{PaO}_{2}$ are not necessarily proportional. Once hyperventilation sets in, blood gas exchange in the patient's alveoli is restricted; $\mathrm{PaO}_{2}$ may also decrease significantly [30]. The results of our meta-analysis have found that compared with NIV, HFNC is more beneficial in reducing the $\mathrm{PaCO}_{2}$ level, length of hospital stay and the incidence of nasal facial skin breakdown, no effect differences in the $\mathrm{PaO}_{2}$, the incidence of tracheal intubation and mortality were found between HFNC and NIV treatments. A similar study published by Yang et al. [31] has compared HFNC and conventional NIV to evaluate the mortality and intubation risk in AECOPD in 8 RCTs and 492 patients, and it had resulted a low-quality evidence for HFNC not increasing mortality and intubation risk. Another meta-analysis published by Huang et al. [32] has showed no differences on $\mathrm{PaO} 2$ levels between patients treated with HFNC vs NIV, but with a smaller study population. In our study, HFNC has showed superiority compared to NIV in hospital LOS and $\mathrm{PaCO}_{2}$ levels, which are different from previous two meta-analyses. The reasons may be that a bias could have occurred in selecting patients, for example including also mild patients, and the included RCTs are from different populations and areas.

HFNC can significantly improve $\mathrm{CO}_{2}$ retention in COPD patients, and its influence on $\mathrm{PaO}_{2}$ levels and tracheal intubation rate needs further study. The results of a multicenter, randomized controlled crossover trial [33] showed that $\mathrm{HFNC}$ reduced $\mathrm{PaCO}_{2}$ levels no less than NIV. At the same time, multiple studies [34, 35] have shown that compared with the long-term oxygen therapy group, HFNC can significantly reduce $\mathrm{PaCO}_{2}$ levels and improve hypercapnia. This may be because HFNC can provide high-flow gas, which can meet or exceed the peak inspiratory flow of patients with dyspnea, thus avoiding the dilution of the inhaled gas due to inhaling too much indoor air [36]. At the same time, it provides high-velocity air flow. By flushing the upper respiratory tract, the mixed gas reduces the ineffective lung anatomy, which not only allows the patient to expel $\mathrm{CO}_{2}$ from the anatomical ineffective cavity during exhalation, but also greatly reduces the repeated inhalation of $\mathrm{CO}_{2}$, thereby 


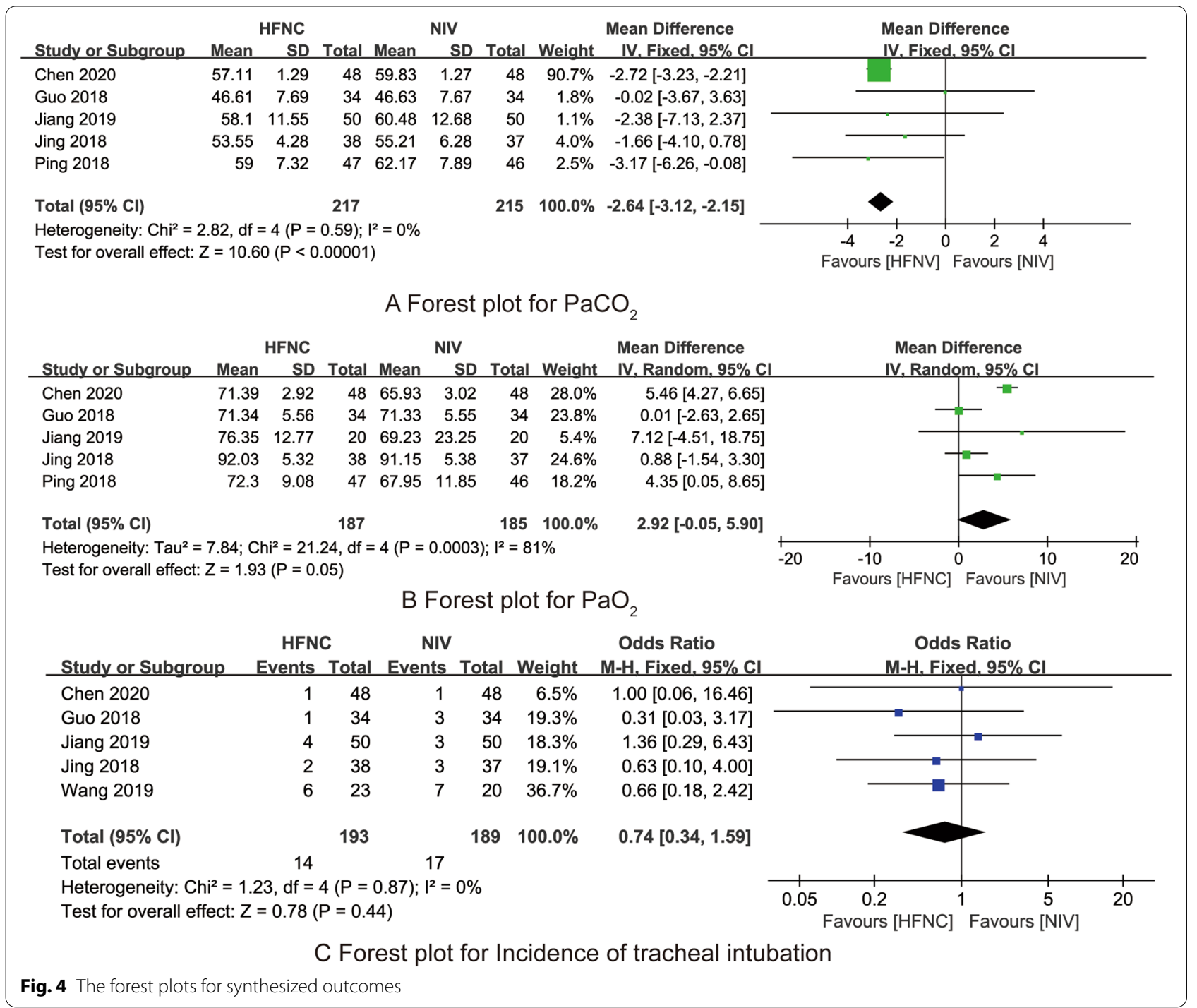

effectively reducing the $\mathrm{PaCO}_{2}$ level $[37,38]$. Theoretically, HFNC can generate a positive end-expiratory pressure of $2-5 \mathrm{cmH}_{2} \mathrm{O}$ to provide sufficient oxygen to enter the alveoli and improve oxygenation [39]. However, compared with NIV, there is no significant difference in efficacy. This may be because although HFNC can produce a certain amount of positive end-expiratory pressure, it does not have the ventilatory support function of NIV [40]. Some patients with weak respiratory muscles may benefit from the ventilatory support function of NIV [41].

HFNC can reduce the occurrence of facial pressure injuries and improve the comfort of COPD patients [42]. HFNC can provide patients with gas heated and humidified up to $37{ }^{\circ} \mathrm{C}$, and the temperature of the gas entering the human body is similar to normal body temperature [43]. HFNC delivers the heated and humidified gas directly to the nasal cavity, which makes up for the insufficient heating and humidification effect of the heating and humidifying gas provided by the NIV when it passes through the pipe or mask because it is not continuously heated and cooled, thereby reducing airway mucosal damage [44]. Moreover, HFNC provides continuous high-flow oxygen through the nasal cannula. Compared with NIV, it can significantly reduce the incidence of pressure injuries such as facial and nasal bridge rupture [45]. HFNC makes up for the insufficient heating and humidification of traditional oxygen therapy, and at the same time avoids the problems of oropharyngeal dryness, intolerance, and facial pressure injury caused by inhalation of pressurized gas in NIV treatment [46]. It is also convenient for patients to cough, eat and talk [47]. 


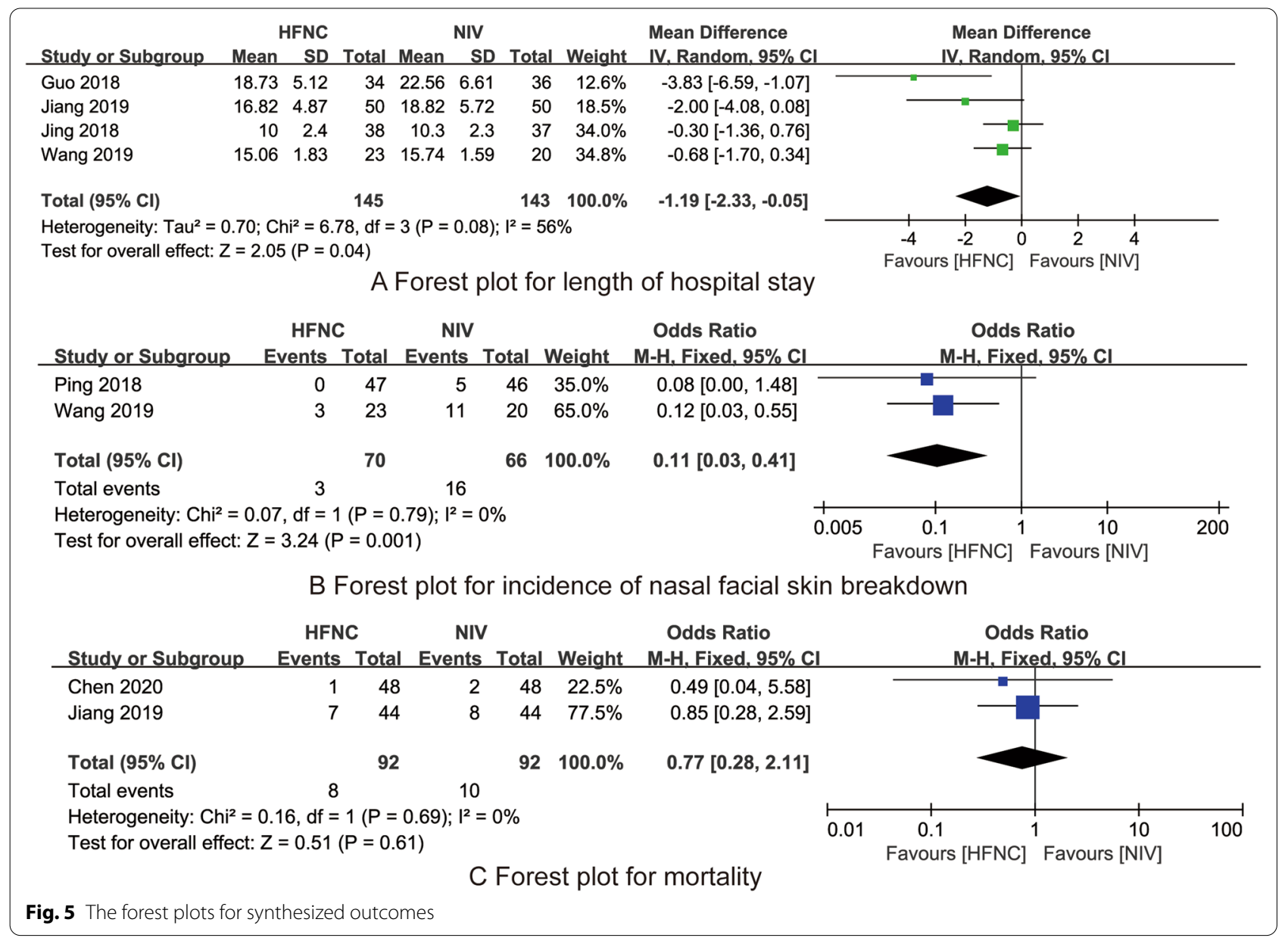

Therefore, HFNC can effectively improve the comfort of patients.

Studies [48, 49] have shown that HFNC treatment can effectively improve the blood gas index of children. Besides, HFNC treatment can effectively improve the heart rate and respiratory rate of patients with acute respiratory failure after extubation of surgically invasive mechanical ventilation. HFNC can continuously provide patients with high-flow oxygen with constant oxygen concentration, and generate positive airway pressure, which can increase the end-tidal volume, help $\mathrm{CO}_{2}$ discharge, reduce physiological dead space, and effectively improve clinical symptoms, thereby improving the results of blood gas analysis [50]. Meanwhile, it can increase the oxygenation index, reduce the average arterial pressure, heart rate and respiratory rate [51].

This study has certain limitations that must be considered. Firstly, the included RCTs are all from China, and the quality of the literature is average, and there may be certain regional and population differences. Therefore, we must be cautious about the authenticity and extrapolation of the results of this study. Secondly, due to the small number of included RCTs and small sample size, the statistical power of the research may be not enough to detect the differences. Thirdly, in this particular period, during COVID-19 epidemic phase, the role of HFNC, which carries large amounts of oxygen, in the correction of $\mathrm{CO}_{2}$ retention is less clear. In the future, multi-center large-sample studies are needed to confirm the exact efficacy and safety of HFNC for COPD patients, and to clarify the specific beneficiaries of COPD patients using HFNC.

\section{Conclusions}

In summary, compared with NIV, HFNC can reduce the $\mathrm{PaCO}_{2}$ level, length of hospital stay and the incidence of nasal facial skin breakdown, and there are not effect differences in the $\mathrm{PaO}_{2}$, the incidence of tracheal intubation and mortality between HFNC and NIV treatments. We recommend HFNC therapy use based on our results, yet currently NIV is more used in some poor or underdeveloped areas with less expenditure and convenience; more studies on the effects and costs of NIV and HFNC 
therapy are needed. This meta-analysis is limited by sample size and quality of included RCTs; more high-quality studies with large sample (better $\geq 166$ cases based on power calculation) in different areas are needed to further elucidate the role of HFNC in the treatment of COPD and respiratory failure.

\section{Abbreviations}

COPD: Chronic obstructive pulmonary disease; NIV: Noninvasive ventilation; HFNC: High-flow nasal cannula; OR: Odds ratio; 95\% Cl: 95\% Confidence interval; MD: Mean difference.

\section{Acknowledgements}

None.

\section{Authors' contributions}

LL designed research; ZX, LZ conducted research; ZX, JZ analyzed data; ZX, $L Z$ wrote the first draft of manuscript; $L L$ had primary responsibility for final content. All authors read and approved the final manuscript.

\section{Funding}

Suzhou Science and Technology Development Plan (No.SS201715)

\section{Availability of data and materials}

All data generated or analyzed during this study are included in this published article.

\section{Declarations}

Ethics approval and consent to participate

Not applicable.

\section{Consent for publication}

Not applicable.

\section{Competing interests}

The authors declare that they have no competing interests.

Received: 9 February 2021 Accepted: 17 September 2021

Published online: 14 October 2021

\section{References}

1. Labaki WW, Rosenberg SR. Chronic obstructive pulmonary disease. Ann Intern Med. 2020;173(3):ITC17-32.

2. Rabe KF, Watz H. Chronic obstructive pulmonary disease. Lancet. 2017;389(10082):1931-40.

3. Gredic M, Blanco I, Kovacs G, Helyes Z, Ferdinandy P, Olschewski H, Barbera JA, Weissmann N. Pulmonary hypertension in chronic obstructive pulmonary disease. Br J Pharmacol. 2021;178(1):132-51.

4. Duffy SP, Criner GJ. Chronic obstructive pulmonary disease: evaluation and management. Med Clin North Am. 2019;103(3):453-61.

5. Hattab Y, Alhassan S, Balaan M, Lega M, Singh AC. Chronic obstructive pulmonary disease. Crit Care Nurs Q. 2016;39(2):124-30.

6. Halpin DMG, Criner GJ, Papi A, Singh D, Anzueto A, Martinez FJ, Agust AA, Vogelmeier CF. Global initiative for the diagnosis, management, and prevention of chronic obstructive lung disease. The 2020 GOLD science committee report on COVID-19 and chronic obstructive pulmonary disease. Am J Respir Crit Care Med. 2021;203(1):24-36.

7. Hanson C, Bowser EK, Frankenfield DC, Piemonte TA. Chronic obstructive pulmonary disease: a 2019 evidence analysis center evidence-based practice guideline. J Acad Nutr Diet. 2021;121(1):139-165e115.

8. Dicker AJ, Huang JTJ, Lonergan M, Keir HR, Fong CJ, Tan B, Cassidy AJ, Finch S, Mullerova $\mathrm{H}$, Miller BE, et al. The sputum microbiome, airway inflammation, and mortality in chronic obstructive pulmonary disease. J Allergy Clin Immunol. 2021;147(1):158-67.
9. Xu S, Ye Z, Ma J, Yuan T. The impact of chronic obstructive pulmonary disease on hospitalization and mortality in patients with heart failure. Eur J Clin Invest. 2021;51(1):e13402.

10. Hong H, Li XX, Li J, Zhang ZQ. High-flow nasal cannula versus nasal continuous positive airway pressure for respiratory support in preterm infants: a meta-analysis of randomized controlled trials. J Matern Fetal Neonatal Med. 2021:34(2):259-66.

11. Suffredini DA, Allison MG. A rationale for use of high flow nasal cannula for select patients with suspected or confirmed severe acute respiratory syndrome coronavirus-2 infection. J Intensive Care Med. 2021;36(1):9-17.

12. Shah $\mathrm{S}$, Kaul A, Bhosale R, Shiwarkar G. High flow nasal cannula therapy as a primary mode of respiratory support in a pediatric intensive care unit. Indian Pediatr. 2021;58(1):41-3.

13. Hill NS. High flow nasal cannula, is there a role in COPD? Tanaffos. 2017;16(Suppl 1):S12.

14. Pisani L, Astuto M, Prediletto I, Longhini F. High flow through nasal cannula in exacerbated COPD patients: a systematic review. Pulmonology. 2019;25(6):348-54.

15. Nishimura M. High-flow nasal cannula oxygen therapy in adults. J Intensive Care. 2015:3(1):15.

16. Criner $\mathrm{G}$. Sorting out the mechanisms of benefit of high flow nasal cannula in stable COPD. Chronic Obstr Pulm Dis. 2017:4(4):259-61.

17. Moher D, Liberati A, Tetzlaff J, Altman DG, Group P. Preferred reporting items for systematic reviews and meta-analyses: the PRISMA statement. PLoS Med. 2009;6(7):e1000097.

18. Higgins JP, Altman DG, Gotzsche PC, Juni P, Moher D, Oxman AD, Savovic J, Schulz KF, Weeks L, Sterne JA, et al. The Cochrane Collaboration's tool for assessing risk of bias in randomised trials. BMJ. 2011;343:5928.

19. Jianjun W, Hongying J, Qing L. A randomized controlled study of transnasal high-flow humidification oxygen therapy and non-invasive positive pressure ventilation in the treatment of acute exacerbations of chronic obstructive pulmonary disease with type II respiratory failure. Chinese Emerg Med. 2019;39(10):945-8.

20. Liu J. Comparison of nasal high-flow oxygen therapy and non-invasive ventilation in chronic obstructive pulmonary disease with respiratory failure. Hebei Medical University; 2018.

21. Liu P, Chuanming G, Lei Q. Comparison of high flow oxygen therapy and non-invasive positive pressure ventilation in the treatment of COPD with respiratory failure. Med J Nat Defend Forces Southwest China. 2018:28(12):1168-70.

22. Liyuan G, Chaohong L, Tiantian W. Clinical study of nasal high-flow oxygen therapy in the treatment of chronic obstructive pulmonary disease in acute exacerbation stage with type II respiratory failure. J Clin Pulmonary Med. 2018;23(7):1337-40.

23. Long C, Dansi Z, Danzhou L. The effect of nasal high-flow humidification oxygen therapy on blood gas analysis indexes and mean arterial pressure in patients with chronic obstructive pulmonary disease and type II respiratory failure. J Clin Exp Med. 2020;19(21):59-63.

24. Xin J. Nasal high-flow oxygen therapy and non-invasive positive pressure ventilation in elderly patients with AECOPD comparative study in early intervention. Hangzhou Zhejiang University of Traditional Chinese Medicine; 2019.

25. Nguyen JMK, Robinson DN, Sidhaye VK. Why new biology must be uncovered to advance therapeutic strategies for chronic obstructive pulmonary disease. Am J Physiol Lung Cell Mol Physiol. 2021;320(1):L1-11.

26. Deshmukh K, Khanna A. Implications of managing chronic obstructive pulmonary disease in cardiovascular diseases. Tuberc Respir Dis (Seoul). 2021;84(1):35-45

27. Ji R, He Q, Zhang R, Gao Z, Ding D. A genetic study of the depressive respiratory responses to hypoxia in chronic obstructive pulmonary disease patients with type II respiratory failure. Zhonghua Yi Xue Yi Chuan Xue Za Zhi. 2000;17(3):173-7.

28. Zhang MC, Wang ZG, Cheng JX, Wang JL, Zheng SP. The study on the value of using the chronic obstructive pulmonary disease and asthma physiology score to assess the severity of acute exacerbation in patients with chronic obstructive pulmonary disease complicated by type II respiratory failure. Zhongguo Wei Zhong Bing Ji Jiu Yi Xue. 2010;22(5):275-8.

29. Hanlon P, Daines L, Campbell C, McKinstry B, Weller D, Pinnock H. Telehealth interventions to support self-management of long-term conditions: a systematic metareview of diabetes, heart failure, asthma, 
chronic obstructive pulmonary disease, and cancer. J Med Internet Res. 2017;19(5):e172.

30. Savi A, Gasparetto Maccari J, Frederico Tonietto T, Pecanha Antonio AC, Pinheiro de Oliveira R, de Mello Rieder M, Zignani EC, Boschi da Silva E, Teixeira $\mathrm{C}$. Influence of $\mathrm{FIO}_{2}$ on $\mathrm{PaCO}_{2}$ during noninvasive ventilation in patients with COPD. Respir Care. 2014;59(3):383-7.

31. Yang PL, Yu JQ, Chen HB. High-flow nasal cannula for acute exacerbation of chronic obstructive pulmonary disease: a systematic review and metaanalysis. Heart Lung. 2021;50(2):252-61.

32. Huang X, Du Y, Ma Z, Zhang H, Jun L, Wang Z, Lin M, Ni F, Li X, Tan H, et al. High-flow nasal cannula oxygen versus conventional oxygen for hypercapnic chronic obstructive pulmonary disease: a meta-analysis of randomized controlled trials. Clin Respir J. 2021;15(4):437-44.

33. Jens B, Dominic D, Andres B. Nasal high- flow versus noninvasive ventilation in patients with chronic hypercapnic COPD. Int J Chron Obstruct Pulmon Dis. 2019;18(12):1411-21.

34. Storgaard LH, Hockey HU, Laursen BS, Weinreich UM. Long-term effects of oxygen-enriched high-flow nasal cannula treatment in COPD patients with chronic hypoxemic respiratory failure. Int J Chron Obstruct Pulmon Dis. 2018:13:1195-205.

35. Hernandez G, Vaquero C, Colinas L, Cuena R, Gonzalez P, Canabal A, Sanchez S, Rodriguez ML, Villasclaras A, Fernandez R. Effect of postextubation high-flow nasal cannula vs noninvasive ventilation on reintubation and postextubation respiratory failure in high-risk patients: a randomized clinical trial. JAMA. 2016;316(15):1565-74.

36. Cortegiani A, Longhini F, Carlucci A, Scala R, Groff P, Bruni A, Garofalo E, Taliani MR, Maccari U, Vetrugno L, et al. High-flow nasal therapy versus noninvasive ventilation in COPD patients with mild-to-moderate hypercapnic acute respiratory failure: study protocol for a noninferiority randomized clinical trial. Trials. 2019;20(1):450.

37. Li J, Jing G, Scott JB. Year in review 2019: high-flow nasal cannula oxygen therapy for adult subjects. Respir Care. 2020;65(4):545-57.

38. Pisani L, Betti S, Biglia C, Fasano L, Catalanotti V, Prediletto I, Comellini V, Bacchi-Reggiani L, Fers SN. Effects of high-flow nasal cannula in patients with persistent hypercapnia after an acute COPD exacerbation: a prospective pilot study. BMC Pulm Med. 2020;20(1):12.

39. Sun J, Li Y, Ling B, Zhu Q, Hu Y, Tan D, Geng P, Xu J. High flow nasal cannula oxygen therapy versus non-invasive ventilation for chronic obstruc tive pulmonary disease with acute-moderate hypercapnic respiratory failure: an observational cohort study. Int J Chron Obstruct Pulmon Dis. 2019;14:1229-37.

40. Bruni A, Garofalo E, Cammarota G, Murabito P, Astuto M, Navalesi P, Luzza F, Abenavoli L, Longhini F. High flow through nasal cannula in stable and exacerbated chronic obstructive pulmonary disease patients. Rev Recent Clin Trials. 2019;14(4):247-60.
41. Di Mussi R, Spadaro S, Stripoli T, Volta CA, Trerotoli P, Pierucci P, Staffieri F, Bruno F, Camporota L, Grasso S. High-flow nasal cannula oxygen therapy decreases postextubation neuroventilatory drive and work of breathing in patients with chronic obstructive pulmonary disease. Crit Care. 2018;22(1):180

42. Nagata K, Kikuchi T, Horie T, Shiraki A, Kitajima T, Kadowaki T, Tokioka F, Chohnabayashi N, Watanabe A, Sato S, et al. Domiciliary high-flow nasal cannula oxygen therapy for patients with stable hypercapnic chronic obstructive pulmonary disease. A multicenter randomized crossover trial. Ann Am Thorac Soc. 2018;15(4):432-9.

43. Spoletini G, Alotaibi M, Blasi F, Hill NS. Heated humidified high-flow nasal oxygen in adults: mechanisms of action and clinical implications. Chest. 2015;148(1):253-61.

44. Spicuzza L, Schisano M. High-flow nasal cannula oxygen therapy as an emerging option for respiratory failure: the present and the future. Ther Adv Chronic Dis. 2020;11:2040622320920106.

45. Vogelsinger H, Halank M, Braun S, Wilkens H, Geiser T, Ott S, Stucki A, Kaehler CM. Efficacy and safety of nasal high-flow oxygen in COPD patients. BMC Pulm Med. 2017;17(1):143.

46. Rittayamai N, Phuangchoei P, Tscheikuna J, Praphruetkit N, Brochard L. Effects of high-flow nasal cannula and non-invasive ventilation on inspiratory effort in hypercapnic patients with chronic obstructive pulmonary disease: a preliminary study. Ann Intensive Care. 2019;9(1):122.

47. Tan $D$, Walline $J H$, Ling B, X Y Y, Sun J, Wang B, Shan X, Wang Y, Cao P, Zhu $Q$, et al. High-flow nasal cannula oxygen therapy versus non-invasive ventilation for chronic obstructive pulmonary disease patients after extubation: a multicenter, randomized controlled trial. Crit Care. 2020;24(1):489.

48. Lin J, Zhang Y, Xiong L, Liu S, Gong C, Dai J. High-flow nasal cannula therapy for children with bronchiolitis: a systematic review and metaanalysis. Arch Dis Child. 2019;104(6):564-76.

49. Luo J, Duke T, Chisti MJ, Kepreotes E, Kalinowski V, Li J. Efficacy of highflow nasal cannula vs standard oxygen therapy or nasal continuous positive airway pressure in children with respiratory distress: a meta-analysis. $\rfloor$ Pediatr. 2019;215:199-208e198.

50. Mayfield S, Jauncey-Cooke J, Hough JL, Schibler A, Gibbons K, Bogossian F. High-flow nasal cannula therapy for respiratory support in children. Cochrane Database Syst Rev. 2014;3:CD009850.

51. Sinha IP, McBride AKS, Smith R, Fernandes RM. CPAP and high-flow nasal cannula oxygen in bronchiolitis. Chest. 2015;148(3):810-23.

\section{Publisher's Note}

Springer Nature remains neutral with regard to jurisdictional claims in published maps and institutional affiliations.
Ready to submit your research? Choose BMC and benefit from:

- fast, convenient online submission

- thorough peer review by experienced researchers in your field

- rapid publication on acceptance

- support for research data, including large and complex data types

- gold Open Access which fosters wider collaboration and increased citations

- maximum visibility for your research: over $100 \mathrm{M}$ website views per year

At BMC, research is always in progress.

Learn more biomedcentral.com/submissions 